\title{
nature
}

\section{Timing is everything}

If you're a morning person, you know how hard it is to function properly late at night. And don't even think of getting a night owl to talk sense at daybreak. Yet our society largely ignores these important differences.

$\mathrm{T}$ he early bird catches the worm. Chi dormi non piglia pesci. Morgenstund hat Gold im Mund. A quien madruga, Dios le ayuda. Most Western languages have a proverb that sings the virtues of the 'larks' who are early to rise - or decries the 'night owls' who need a lie-in to recover from their exertions of the night before.

In the pre-electric era, this made sense: people had to make the most of limited daylight. Today, living in an artificially illuminated '24/7' society, there is no good reason to hold earlier risers in especially high esteem. But if we are all to perform optimally, there is every reason to pay more attention to the underlying biological rhythms that determine our daily, or circadian, patterns of activity. Too many of us find ourselves working against our body's natural rhythms, rather than with them. And that's bad news, for both our quality of life and our economic productivity.

Circadian biologists have long known that our daily cycles of sleep and wakefulness, hormone levels and body temperature, vary dramatically in phase between individuals. The norm may be to take eight hours' sleep between 11 p.m. and 7 a.m., but people's natural preferences vary, giving a normal distribution across the population that can put two individuals' preferred bed-times out of synch by up to eight hours. Researchers even have a specific label to describe the phase of an individual's body rhythms: their 'chronotype'.

The phase of our circadian rhythms varies with age, and it is now emerging that it can be seriously disrupted by a variety of diseases (see page 896). But for most healthy adults, the underlying chronotype is extremely difficult to shift.

Given what we already know about circadian biology, certain aspects of modern life seem perverse. Adolescents are notorious night owls, yet in some countries the school day starts so early that only the extreme outliers on the normal distribution are likely to function properly in the first lesson of the day. Is it any wonder that teachers are frequently faced with a class full of sullen, disinterested students?

In countries such as the United States and Germany, where some $20 \%$ of the working population does shift work, employers are only now starting to consider what circadian biology has to offer. Should the selection of workers for particular shifts take their chronotypes into account? Is the common practice of rotating staff between different shift rotations a recipe for industrial unrest and shoddy work?

Certainly, the measurements that have been made so far suggest that people don't readily adjust to a new working day. But we don't have firm answers to these questions, because too few studies have been done. Employers and governments are starting to recognize that more field data are needed. But moving the field of circadian biology from its current fringe position will require earmarked funding and a determined effort to raise its profile within the world's biomedical researcher agencies. At present, circadian biology remains a crossdisciplinary orphan that has few champions in the committees that decide where the grant money goes. It's time for that to change.

\section{Don't create a climate of fear}

US researchers studying sexual behaviour, drug use and other controversial topics need protection from political interference.

T his month, 180 researchers funded by the US National Institutes of Health (NIH) started getting phone calls from the agency's headquarters in Bethesda, Maryland. The researchers were told that their names were on a list held by a Congressional committee that oversees the NIH, and that they might expect inquiries from its investigators.

The researchers concerned have done nothing wrong, but they have offended the moral sensibilities of conservative lobbyists - so they have every reason to be worried. Their 'crime' is to have convinced their scientific peers that their research into homosexuality, sexually transmitted diseases, the use of illegal drugs and other subjects is important for public health, and therefore worthy of NIH grants.

A spokesman for the House of Representatives' energy and commerce committee says that it does not plan to investigate the researchers' work formally. But the list, compiled by a religious lobbying group, has already drawn the attention of prominent Republican members of Congress. At a Congressional hearing on 2 October, they asked the NIH to explain the medical and public-health relevance of the highlighted projects. So the NIH began preparing a case to "place the research within the context of the agency's scientific mission and strategic research plan", and started calling researchers on the list to warn them that their work could be scrutinized.

This is the second time this year that the Congress has turned a spotlight onto projects that have already been vetted by the peerreview process. In July, the House of Representatives voted by a tiny margin not to remove funding from five grants that had been singled out because they touched on such issues as female sexuality and pornography.

Every US taxpayer is entitled to hold an opinion on the merits of NIH-funded research. But not every taxpayer is an expert on the public-health needs of the United States, and neither are all of their elected representatives. This is why the government asks suitably qualified experts to recommend projects that deserve funding.

Congress has a right to ask questions about how well the peerreview process works. But applying such pointed scrutiny to individual investigators whose grants have already been funded will have a chilling effect, scaring scientists away from studying issues that may be crucial for the health and well-being of society as a whole.

These moves come at a time when the NIH is being asked whether many of its administrative functions can be outsourced to the private sector (see page 888 ). Federal agencies must be expected to demonstrate that they are efficiently run, but the pressures currently being brought to bear on the NIH are denting morale. If members of Congress aren't careful, they will undermine the integrity of the world's leading biomedical research agency, and ultimately threaten their constituents' health. 